Article

\title{
Nitrogen-Doped Graphene Iron-Based Particle Electrode Outperforms Activated Carbon in Three-Dimensional Electrochemical Water Treatment Systems
}

\author{
Hosna Ghanbarlou ${ }^{1, *}$, Nikoline Loklindt Pedersen ${ }^{2}$, Morten Enggrob Simonsen ${ }^{2} \mathbb{D}$ and \\ Jens Muff 2,*(D) \\ 1 Department of Chemical Engineering, Amirkabir University of Technology, 15875-4413 Tehran, Iran \\ 2 Section of Chemical Engineering, Department of Chemistry and Bioscience, Aalborg University, 6700 Esbjerg, \\ Denmark; loklindt.niko@hotmail.com (N.L.P.); mes@bio.aau.dk (M.E.S.) \\ * Correspondence: h.ghanbarlou@aut.ac.ir (H.G.); jm@bio.aau.dk (J.M.)
}

Received: 7 October 2020; Accepted: 4 November 2020; Published: 7 November 2020

check for updates

\begin{abstract}
The synergy between electrochemical oxidation and adsorption on particle electrodes was investigated in three-dimensional (3D) systems for p-nitrosodimethylaniline (RNO) decolorization and pesticide removal. A comparison was made between granular activated carbon (GAC) and a novel synthesized nitrogen-doped graphene-based particle electrode (NCPE). Experiments on RNO decolorization show that the synergy parameter of the 3D-NCPE system was improved 3000 times compared to the studied 3D-GAC system. This was due to the specific nanostructure and composition of the NCPE material. Nitrogen-doped graphene triggered an oxygen reduction reaction, producing hydrogen peroxide that simultaneously catalyzed on iron sites of the NCPEs to hydroxyl radicals following the electro-Fenton (EF) process. Data showed that in the experimental setup used for the study, the applied cell voltage required for the optimal value of the synergy parameter could be lowered to $5 \mathrm{~V}$ in the 3D-NCPEs process, which is significantly better than the $15-20 \mathrm{~V}$ needed for synergy to be found in the 3D-GAC process. Compared to previous studies with 3D-GAC, the removal of pesticides 2,6 dichlorobenzamide (BAM), 2-methyl-4-chlorophenoxyaceticacid (MCPA), and methylchlorophenoxypropionic acid (MCPP) was also enhanced in the 3D-NCPE system.
\end{abstract}

Keywords: three-dimensional electrochemical water treatment; synergy parameter; nitrogen-doped graphene; activated carbon; pesticide removal

\section{Introduction}

Electrochemical oxidation is an emerging technology that has been effectively used for the removal of organic pollutants from water and is appropriate to be implemented as part of a decentralized water treatment system [1]. The use of a bed material inside the reactor as a third electrode can effectively increase the specific surface area of the electrodes [2-4]. For example, Li et al. [5] used a ceramic particle electrode for the electrochemical degradation of 2-diethylamino-6-methyl-4-hydroxypyrimidine in a three-dimensional electrode reactor. There are also reports showing that the combination of metals and ceramic materials as particle electrodes could be effective in promoting 3D-electrochemical water treatment processes [6-8].

Granular activated carbon (GAC) is widely studied as a third electrode due to its interesting surface properties such as high surface area, high porosity and active surface chemistry [9-12]. The improvement of three-dimensional electrochemical systems (using GACs as the third electrode) was attributed to its extensive specific surface area [13-15] and the ability of carbon materials to 
promote the generation of hydrogen peroxide by an oxygen reduction reaction [16-18]. Nevertheless, when GAC is applied as the third electrode, the efficiency of the technology depends mostly on the adsorption properties of the organic micropollutants $[19,20]$. For instance, some compounds such as phenoxy-acid herbicides have less tendency to adsorb to the carbon [10], resulting in low adsorption capacity and low removal efficiency in these systems. Research on technologies for the removal of persistent organic contaminants including pesticides from groundwater has been the focus for several years, either as part of groundwater-based drinking water production or as pump-n-treat solutions used in groundwater remediation. In countries such as Denmark, research in this area has recently increased $[10,21,22]$ due to large non-target analytical screenings of groundwater aquifers revealing significant pesticide contamination of a greater extent than previously expected [21-23]. Therefore, the development of efficient and cost-effective treatment technologies for pesticides removal is of high concern.

The removal and degradation mechanisms of contaminants in three-dimensional electrochemical systems are a complex interplay between surface adsorption processes and electrode surface and particle surface electrochemical reactions. Synergy between these removal pathways usually leads to increased treatment efficiency and lower overall treatment costs compared to the removal of the individual processes alone or the additive removal in series. Therefore, enhancement of the synergy parameter is important for optimization of the three-dimensional electrochemical system. The synergy parameter has been studied by a few researchers in three-dimensional systems using GACs as particle electrode $[9,10,20]$. In the work of Zhu et al., it was found that synergy not only resulted from direct electrochemical oxidation at activated carbon, but also the electrocatalysis of activated carbon to indirect electrochemical oxidation mediated by hydroxyl radicals [9]. Garcia reported positive values of synergy for COD (Chemical Oxygen Demand) and TOC (Total Organic Carbon) removal (i.e., $28 \%$ and $30 \%$, respectively) using granular activated carbon as a particle electrode, which further demonstrated that the combination of adsorption and electrochemical oxidation triggered electroadsorption and electrocatalytic reactions at the surface of GAC, showing a better performance than their superposed operation. Pedersen et al. explored the synergy of GAC adsorption and electrochemical degradation in the mineralization of pesticides. Their results indicated that synergies of 121-126\% were obtained for pesticides removal, including 2-methyl-4-chlorophenoxyaceticacid (MCPA) and methylchlorophenoxypropionic acid (MCPP) in electric field strength of $375 \mathrm{~V} / \mathrm{m}$ [10].

Although in these studies the presence of activated carbon improved water treatment efficiency, most of this progress was due to the adsorption characteristics of GAC and not the electrochemical properties, making the synergy values low in these systems. Therefore, it is necessary to look for a particle electrode material that can be more easily polarized within the electric field of a 3D system in order to increase the synergy parameter.

An oxygen reduction reaction (ORR) is an essential reaction in electrochemical oxidation processes, since it produces hydrogen peroxide, which is an important intermediate for hydroxyl radical production. There are several papers in recent years showing that nitrogen-doped carbon nanomaterials are effective electrocatalysts toward oxygen reduction reactions [24-29]. Research in this area shows that catalysts containing nitrogen-doped carbon nanomaterials (including graphene, carbon nanotubes, mesoporous carbon, etc.) can greatly enhance the oxygen reduction reaction efficiency [30-32]. Even in some cases, such electrocatalysts have been capable of outperforming rare and expensive platinum-based catalysts [33,34]. It was also found that pyridinic and graphitic nitrogen species are responsible for the improved activity of catalysts in these nitrogen-doped carbon nanomaterials [35,36]. Koutecký-Levich plots showed that oxygen reduction reaction on nitrogen-doped graphene is a combination of two-electron and four-electron pathways considering the calculated number of transferred electrons $[37,38]$. This means that hydrogen peroxide could be produced at least as an intermediate during the reductive reactions. On the other hand, other studies reported that ORR is less likely to occur through the 4e- pathway in acidic media, and alkaline media is favorable for 4ereduction of oxygen $[39,40]$. It has also been demonstrated that by decreasing applied potential and 
current density, the number of transferred electrons decreases, while the amount of produced hydrogen peroxides increases [41,42].

The presence of iron components in graphene-based catalysts on the other hand could promote the electro-Fenton (EF) process, which is important for hydroxyl radical production [43-46]. This can cause a significant increase in the synergy of the process. Therefore, the combination of carbon-iron $[45,47]$ or nitrogen-doped carbon and iron species [19] are considered interesting to stimulate electro-oxidation and reduction processes, leading to a higher synergy parameter. As mentioned before, this higher synergy would increase efficiency, thus reducing the energy consumption and costs of the treatment process.

In our previous work, a novel nanostructure of nitrogen-doped catalytic particle electrode (NCPE) was synthesized [19]. The morphological characterization of synthesized NCPEs demonstrated the presence of a raspberry-like nanostructure of graphene sheets and iron nanocrystals. It was found by Raman spectroscopy that synthesized graphene had high levels of graphitization, and XPS characterization also revealed high amount of nitrogen doping with a higher ratio of pyridinic and graphitic nitrogen types. These kinds of nitrogen were found to be effective for promoting oxygen reduction reactions, while iron nanoparticles trigger Fenton's reaction at the same time.

In previous work, synergy has only been investigated for activated carbon-based catalysts, so the novelty of the current study is to study the synergy using the NCPE material. We aim to develop a strategy for increasing the synergy parameter by promoting electrochemical properties of synthesized catalyst materials. The synergy parameter for synthesized catalysts at different applied cell voltages was evaluated followed by a comparison of the results to a similar process using activated carbon as particle electrodes. Then, the removal rates of the pesticides 2,6 dichlorobenzamide (BAM), 2-methyl-4-chlorophenoxyaceticacid (MCPA), and methylchlorophenoxypropionic acid (MCPP) was studied at the optimum voltage of the synergy parameter. In this study, p-nitrosodimethylaniline (RNO) is used as model pollutant, as it is present in effluents from the production of explosives, dyestuffs, pesticides and herbicides, and the bleaching of RNO has been reported to be very selective to oxidation by hydroxyl radicals [48].

\section{Materials and Methods}

\subsection{Materials and Chemical Reagents}

Prussian blue $\left(\mathrm{Na}_{4} \mathrm{Fe}(\mathrm{CN})_{6} \times 10 \mathrm{H}_{2} \mathrm{O}\right)$ was purchased from Sigma-Aldrich (Søborg, Denmark). Activated carbon (RESPCARB BRI, $12 \times 20$ US RGF 3191) was supplied from Chemviron Carbon (Feluy, Belgium), 2-methyl-4-chlorophenoxyaceticacid (MCPA) (CAS: 94-74-6), methylchlorophenoxypropionic acid (MCPP) (CAS: 93-65-2) and 2,6 dichlorobenzamide (BAM) (CAS: 2008-58-4) of analytical grade were all obtained from Sigma Aldrich (Søborg, Denmark). Reagents, including $\mathrm{FeSO}_{4} \times 7 \mathrm{H}_{2} \mathrm{O}$, $\mathrm{H}_{2} \mathrm{SO}_{4}, \mathrm{NaOH}$, and solvents of analytical grade (all Sigma-Aldrich, Søborg, Denmark), were used as such without any further processing. All solutions were prepared with deionized water except otherwise mentioned.

\subsection{Synthesis of Nitrogen-Doped Catalytic Particle Electrodes (NCPEs)}

The detailed protocol for synthesis of the NCPE material and characterization of the material is published in our earlier work [19]. In brief, $\mathrm{Na}_{4} \mathrm{Fe}(\mathrm{CN})_{6} \times 10 \mathrm{H} 2 \mathrm{O}$ (Prussian blue) was dried in an oven at $150{ }^{\circ} \mathrm{C}$ for $24 \mathrm{~h}$ before annealing in a low nitrogen flow rate at $900{ }^{\circ} \mathrm{C}$ for $3 \mathrm{~h}$ in a tube furnace (EHA 12/450B horizontal tube furnace, CARBOLITE, Sheffield, UK) with a heat-up rate of $5^{\circ} \mathrm{C} / \mathrm{min}$ to convert it to the hybrid material. After cooling down to room temperature, the nitrogen-doped catalytic particle electrode (NCPE) was obtained by washing with deionized water, vacuum filtration, and drying at $65^{\circ} \mathrm{C}$ for $24 \mathrm{~h}$. 


\subsection{Morphological Characterization}

Morphological analysis of synthesized particle electrodes was performed by scanning electron microscopy (SEM) using a ZEISS instrument (Jena, Germany). Elemental analysis (EDS (Energy-dispersive X-ray spectroscopy) mapping) of synthesized particle electrodes was also investigated by Field-Emission Scanning Electron Microscopy (FESEM MIRA3, TESCAN, Brno, Czech Republic).

\subsection{Experimental Set-Up and Procedure}

Electrocatalytic evaluation of the synthesized particle electrodes was conducted in a $700 \mathrm{~mL}$ cylindrical single compartment cell using Mersan DC $(0-20 \mathrm{~V} \pm 0.1 \mathrm{~V})$ as the power supply (Istanbul, Turkey). RNO solution (in deionized (DI) water) was prepared with conductivity of $\approx 6$ to $7 \mu \mathrm{S} / \mathrm{cm}$, and no additional electrolytes were used for all experiments except otherwise mentioned. Electrochemical degradation using different particle electrodes was performed under constant stirring at ambient temperature $\left(22 \pm 1{ }^{\circ} \mathrm{C}\right)$, particle electrodes were added by considering the ratios of $1 \mathrm{mg}_{\text {catalyst }}$ per $\mathrm{mL}$ of the feed solution. Electrochemical treatment experiments in 2D and 3D systems (with (3D) and without (2D) particle electrodes) were performed in a laboratory setup, as shown in Figure 1. The electrolytic cell was comprised of $\mathrm{Nb} / \mathrm{BDD}$ anode and AISI 316 stainless steel cathode (Electrocell A/S, Tarm, Denmark) with submerged active electrode areas of $30 \mathrm{~cm}^{2}$ each and an electrode gap of $4.0 \mathrm{~cm}$.

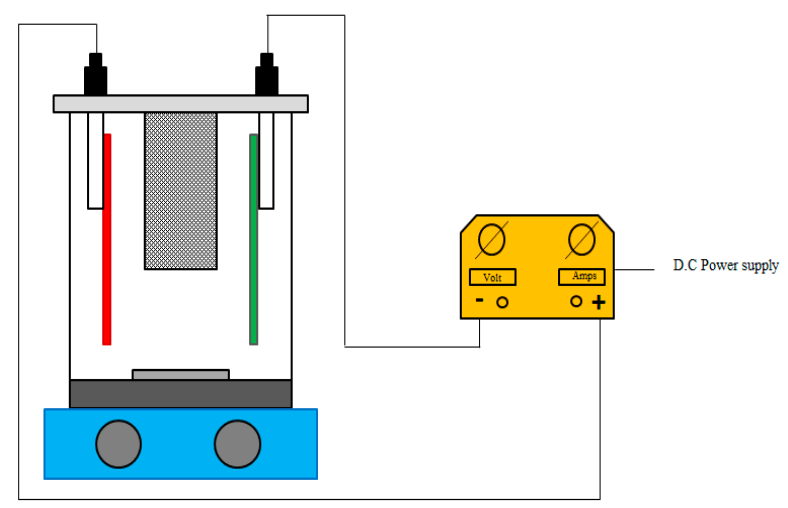

Figure 1. Schematic diagram of the three-dimensional electrode batch reactor.

A nylon gasket $(2 \times 2 \times 4 \mathrm{~cm})$ was set between the electrodes fixating the particles within the electric field and allowing movement at the same time. The initial concentration of RNO was $10 \mathrm{mg}$ RNO/L for RNO decolorization experiments, and $500 \mathrm{~mL}$ of the feed solution was considered as the working volume for the electrocatalytic experiments. Due to the low conductivity ( $\approx 6$ to $7 \mu \mathrm{S} / \mathrm{cm}$ ) of the solvent, the resulting current was in the range of $0-400 \mathrm{~mA}$.

To compare the electrochemical performance of synthesized NCPEs with that of GAC as the particle electrode, activated carbon was washed in deionized water, vacuum filtered, and dried at $105^{\circ} \mathrm{C}$ for $24 \mathrm{~h}$ before electrochemical treatment experiments.

The 3D electrochemical experiments for the degradation of pesticides were carried out using a $50 \mathrm{mg} / \mathrm{L}$ mixed solution of BAM, MCPA, and MCPP in deionized water. All experiments were performed at the natural $\mathrm{pH}$ of the deionized water $(\approx 5.6)$.

In order to investigate the effect of background electrolyte on the RNO decolorization performance of the synthesized NCPEs, $0.05 \mathrm{M}$ sodium sulfate and tap water from Esbjerg (Denmark) was used as background electrolyte. The composition of major ions in the tap water is listed in Table $1[10,21,22]$. 
Table 1. Ionic composition (major ions) of Esbjerg tab water (mg/L).

\begin{tabular}{cccccc}
\hline Calcium & Magnesium & Sodium & Chloride & Nitrate & Sulfate \\
\hline 37.7 & 4.9 & 19.0 & 44.8 & 0.5 & 16.6 \\
\hline
\end{tabular}

\subsection{Analytical Methods}

The rate of RNO decolorization was analyzed using UV-vis spectrophotometry at the $440 \mathrm{~nm}$ maximum absorbance peak. Linear calibration was made in the 1 to $10 \mathrm{mg} / \mathrm{L}$ interval with $R^{2}=0.996$.

Concentrations of BAM, MCPA, and MCPP were evaluated using an HPLC/MS-MS (Thermo Scientific Dionex UltiMate 3000/TSQ Vantage, Roskilde, Denmark) equipped with an ACQUITY UPLC BEH C18, $1.7 \mu \mathrm{m}$, column. A mixture of methanol $(60 \%)$ and $5 \mathrm{mM}$ ammonium acetate buffer solution $(\mathrm{pH}=3)(40 \%)$ (formic acid was used to adjust the $\mathrm{pH})$ was used as the eluent. The determination was performed with a flow rate of $0.35 \mathrm{~mL} / \mathrm{min}$, injection volume of $4 \mu \mathrm{L}$, column temperature at $40{ }^{\circ} \mathrm{C}$, and a detection limit of $0.01 \mathrm{mg} / \mathrm{L}$.

\subsection{Evaluation Parameters}

The decolorization ratio of RNO was calculated according to Equation (1).

$$
\text { Decolorization percentage }=\left(1-A_{t} / \mathrm{A}_{0}\right) \times 100
$$

The rate constant of decolorization of RNO was determined by the pseudo-first-order reaction shown in Equation (2)

$$
\ln \left(\mathrm{C}_{0} / C_{t}\right)=\mathrm{k}_{\mathrm{obs}} t .
$$

$\mathrm{A}_{0}$ and $A_{t}$ are the absorbance of the dye solution initially, and at time $\mathrm{t}, t$ is the reaction time (min), $\mathrm{k}_{\mathrm{obs}}$ is the apparent rate constant $\left(\mathrm{min}^{-1}\right)$, and $\mathrm{C}_{0}$ and $C_{t}$ are concentrations at times of $\mathrm{t}=0$ and $\mathrm{t}=t$, respectively.

The experimental results for pesticides were assessed with concentration removal rate $\left(\eta_{t}\right)$, which is expressed as shown in Equation (3):

$$
\eta_{\mathrm{t}}=\left(\mathrm{C}_{0}-\mathrm{C}_{t}\right) / \mathrm{C}_{0} \times 100 .
$$

The kinetic models were represented by Equations (4)-(6) for particle electrodes adsorption, 2D and 3D electrochemical processes, respectively:

$$
\begin{gathered}
\text { Adsorption }: r=\frac{d[C]}{d t}=-k_{A d} \cdot[C] ; k_{A d}=k \cdot[P E]_{0} \\
\text { 2D Elec. }: r=\frac{d[C]}{d t}=-k_{2 D} \cdot[C] ; k_{2 D}=k \cdot\left[O H^{\bullet}\right]_{0} \\
3 D \text { Elec. }: r=\frac{d[C]}{d t}=-k_{3 D} \cdot[C] ; k_{3 D}=k \cdot\left[O H^{\bullet}\right]_{0} \cdot[P E]_{0}
\end{gathered}
$$

$[C]$ denotes the concentration of organic molecules RNO, MCPA, MCPP, and BAM. PE refers to particle electrodes and $k_{A d}, k_{2 D}$, and $k_{3 D}$ refer to the kinetic constants of adsorption, two-dimensional, and three-dimensional processes, respectively. The potential synergy of the $3 \mathrm{D}$ process, $S$, was calculated according to Equation (7):

$$
S=\frac{k_{3 D}-k_{2 D}-k_{A d}}{k_{2 D}+k_{A d}} \cdot 100
$$




\section{Results and Discussion}

\subsection{Morphological Characterization}

The SEM image in Figure 2 clearly shows that the raspberry-like nanostructure of the graphene particles in combination with iron nanocrystal was formed during the synthesis process. This threedimensional nanostructure could be very effective for exposing active sites to the reactants as the ORR electrochemical process take place. It can provide sufficient channels for both electrons and ions transfer during the oxygen reduction reaction. In addition, it was clear from the EDS mapping of the nanocatalyst surface that a good distribution of nitrogen and iron species was achieved by the applied synthesis method, which plays an important role in creating active sites on the catalyst surface for the ORR.
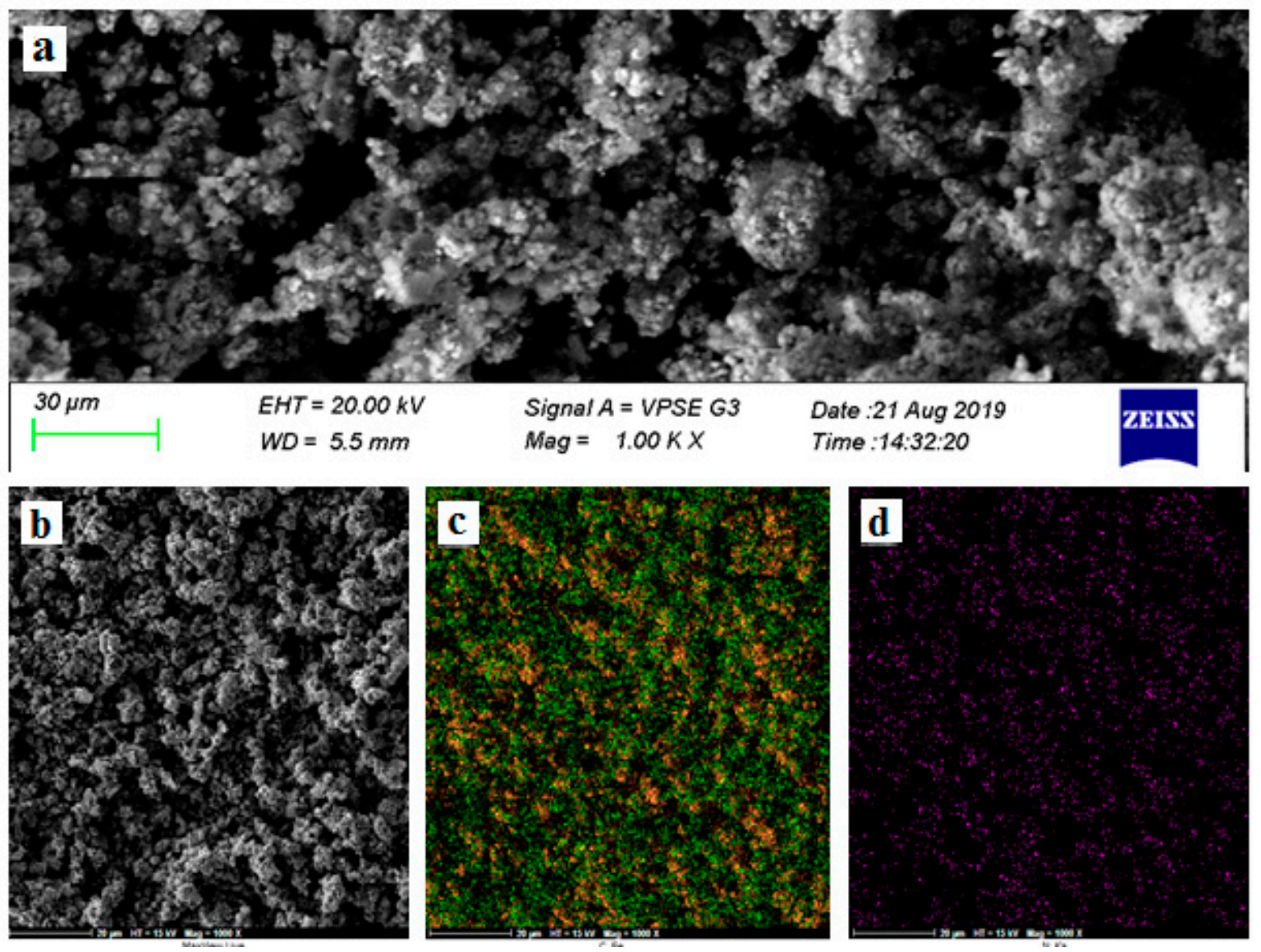

Figure 2. (a) SEM images of Fe3C@N-GE-Fe3O4 hybrid. FESEM-EDS images of (b) catalyst surface, (c) iron and (d) nitrogen elemental distribution.

It is worthwhile to mention that a full characterization report of the synthesized NCPEs can be found in our earlier paper [19].

\subsection{Synergy Parameter Investigation for RNO Decolorization}

Decolorization of the yellow color of the RNO solution was used to track the organic removal processes. The currents were below $0.3 \mathrm{~A}$ because of the low conductivity of the demineralized water matrix, so the decolorization rates were in general much slower than previously reported for electrochemical 2D BDD (Boron Doped Diamond) RNO decolorization performed in $0.1 \mathrm{M}$ sodium sulfate supporting electrolytes also operated galvanostatically at higher current densities [48]. A 3D RNO decolorization was performed using unsaturated NCPEs throughout $360 \mathrm{~min}$, and the result was compared with the performance of unsaturated GACs, as illustrated in Figure 3. The corresponding 
kinetic rates are also shown in order to calculate the synergy parameter. As shown in the synthesized catalyst RNO decolorization curves (Figure $3 a, b$ ), this catalyst has a slow rate of adsorption while being able to decolorize RNO up to $91 \%$ in the 3D system within the $6 \mathrm{~h}$ experiment. As expected, the decolorization rate of RNO by activated carbon was almost the same in single adsorption and $3 \mathrm{D}$ processes, which decreased the value of the synergy parameter in the 3D-GAC system. To compare the performance of the synthesized NCPEs with that of GACs for the RNO decolorization process, the synergy parameter for both catalysts was calculated using Equation (7) to be 3547\% and 3\% for 3D-NCPEs and 3D-GACs systems, respectively.

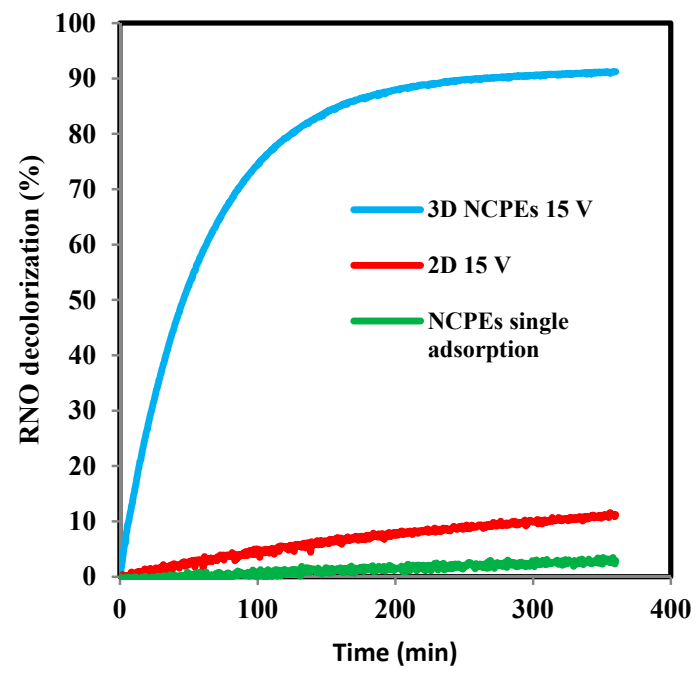

(a)

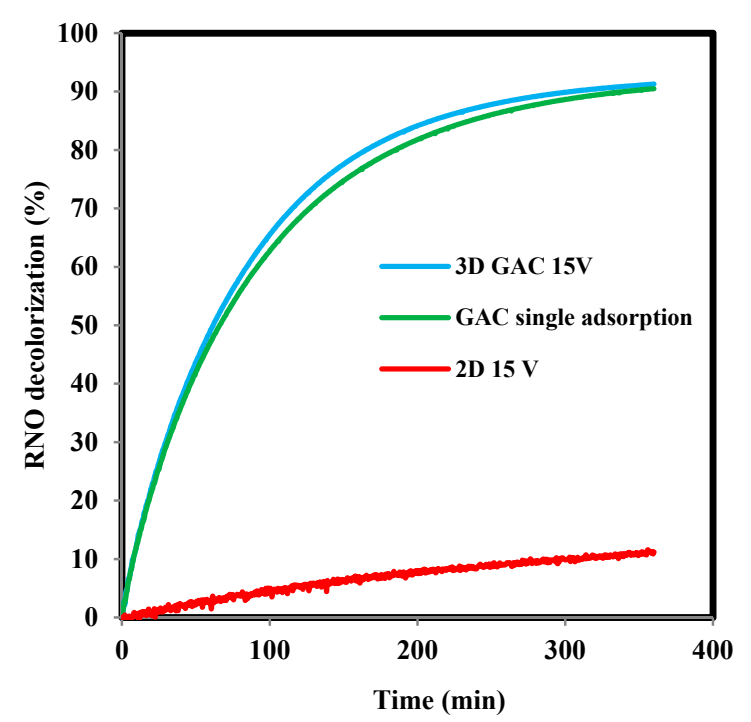

(c)

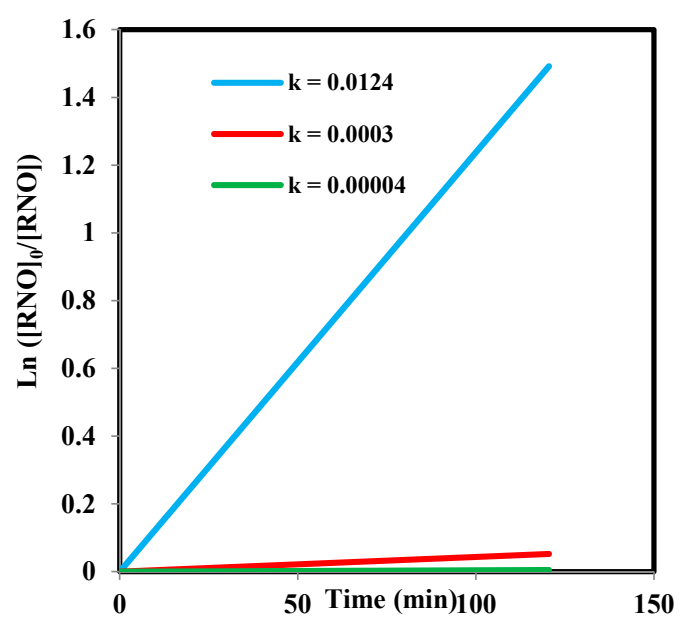

(b)

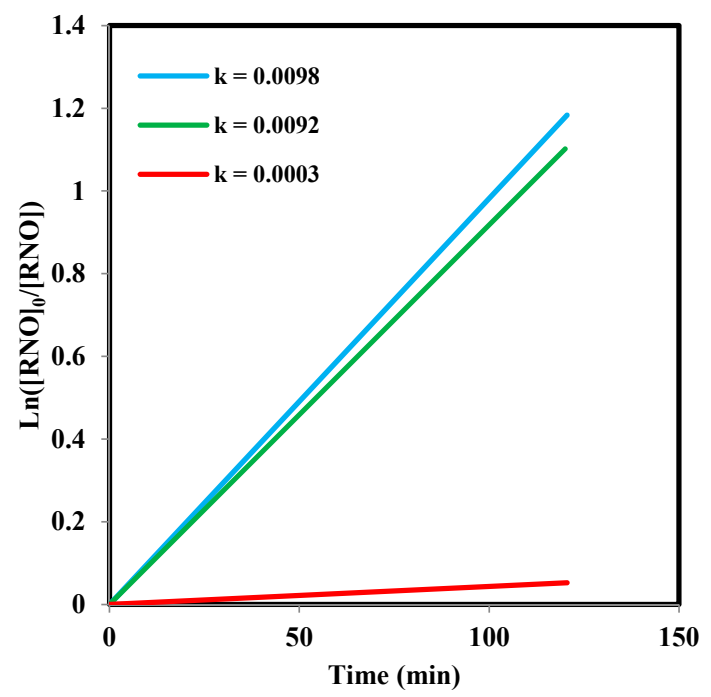

(d)

Figure 3. $(\mathbf{a}, \mathbf{b})$ p-nitrosodimethylaniline (RNO) decolorization with corresponding kinetic rates in 3D systems using nitrogen-doped graphene-based particle electrode (NCPE) as particle electrodes; (c,d) RNO decolorization with corresponding kinetic rates using granular activated carbon (GAC) as particle electrodes in 3D systems. 
The considerably large difference between the synergy parameter of the NCPE material and the activated carbon $(\approx 3543 \%)$ shows that the combination of the two-dimensional system with particle electrodes will improve the performance of the system more significantly in the case of NCPEs than the GACs. This can be attributed to the electrocatalytic properties of the synthesized catalyst, whereas activated carbon has poor intrinsic electrocatalytic characteristics. Nitrogen-doped graphene in the structure of NCPEs boosts electrical conductivity and promotes the oxygen reduction reaction. In addition, the presence of iron particles in this catalyst improves the electro-Fenton reaction and the production of hydroxyl radicals. On the other hand, since activated carbon only has minor electrochemical activity toward the oxygen reduction reaction associated with high adsorption capabilities, the large difference in the obtained synergy parameter seems rational.

It is worth noting that the removal rates in 3D-NCPEs and 3D-GACs systems are so close, but the advantage of using NCPEs as a third electrode is that it could promote electrochemical reactions because of its intrinsic electrochemical characteristics during the whole treatment process, whereas the adsorption capacity of GACs could be deactivated after a certain period of time of treatment and would not be an effective characteristic anymore.

\subsection{RNO Decolorization Versus Applied Cell Voltage}

In order to find the optimal synergy point for NCPE material and to make a comparison with activated carbon, the synergy was investigated at different applied cell voltages.

To find the maximum point for the synergy parameter, the conventional 2D electrochemical process for RNO bleaching by the stationary electrode surface reactions was studied under potentiostatic conditions at different cell voltages $(5,10,15$, and $20 \mathrm{~V})$. Considering the pseudo-first-order kinetics for the RNO bleaching reaction, the rate constants in each voltage were calculated. This was also followed for the 3D electrochemical treatment of RNO solution using GACs and NCPEs as particle electrodes. Therefore, with the adsorption rate constants for both electrocatalysts obtained from the previous stage (kinetic correlation within $120 \mathrm{~min}$ ), it was possible to calculate the synergy at each voltage. The RNO degradation curves with corresponding kinetic rates in each voltage for 2D (a and b), 3D-GACs (c and d), and 3D-NCPEs (e and f) are shown in Figure 4.

As expected for RNO decolorization curves using GACs in the 3D process, no significant change was observed in the system by changing cell voltage. As earlier mentioned, most of the pollutant removal by GACs was attributed to its high adsorption properties rather than its electrochemical characteristics. Slight increases in RNO decolorization were observed by increasing the voltage from 5 to $20 \mathrm{~V}$ in the 3D-GACs process; however, there were no considerable changes. This is distinctly different for the synthesized particle electrode, and as it is clear from the RNO decolorization curves for the 3D-NCPEs system with changing voltage from 5 to 10 and $15 \mathrm{~V}$, a remarkable difference in RNO decolorization rate appeared (65.4\% and $138 \%$ improvement, respectively), indicating the electrochemical properties of the synthesized NCPEs. A subtle change in the RNO decolorization after 15 volts indicates that a further increase in voltage only enhanced the side reactions, which have a deterrent role in the hydroxyl radical production and thus do not lead to further improvement in the decolorization process. 


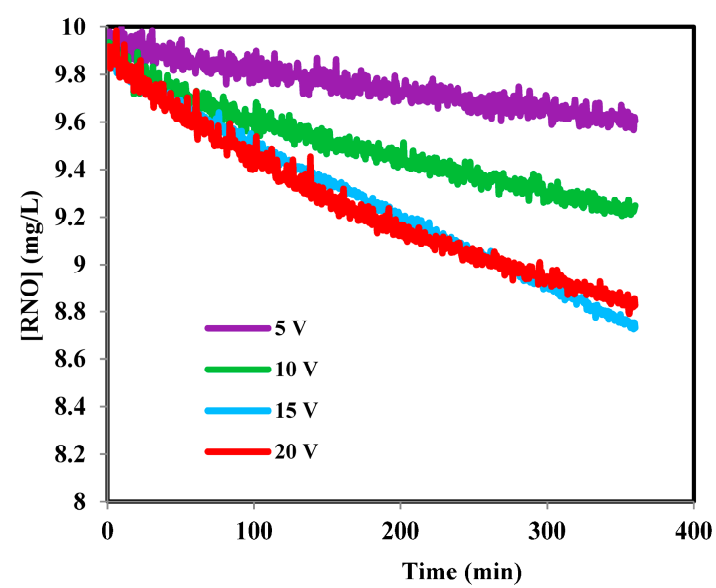

(a)

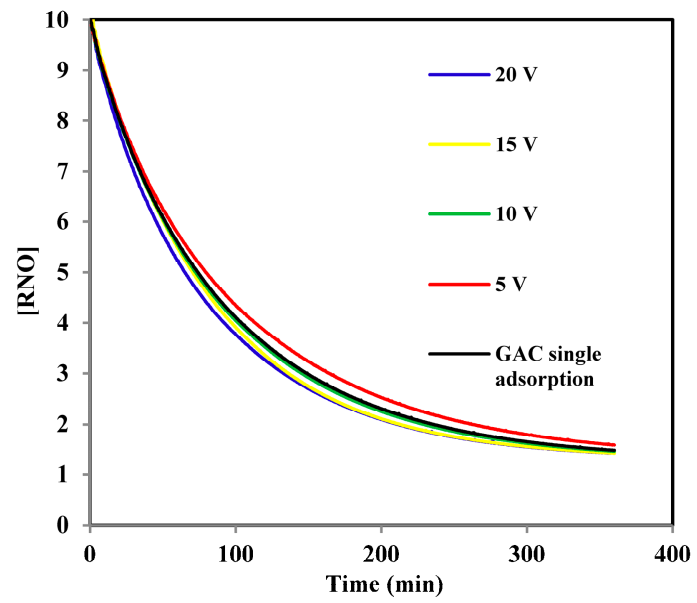

(c)

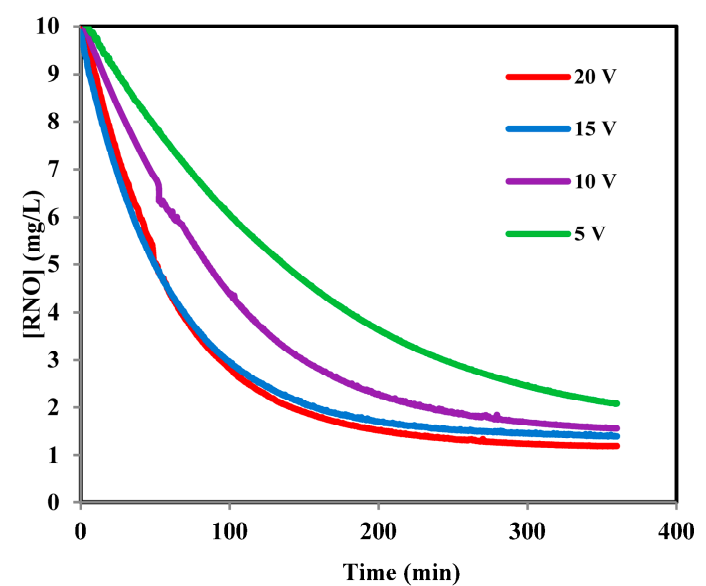

(e)

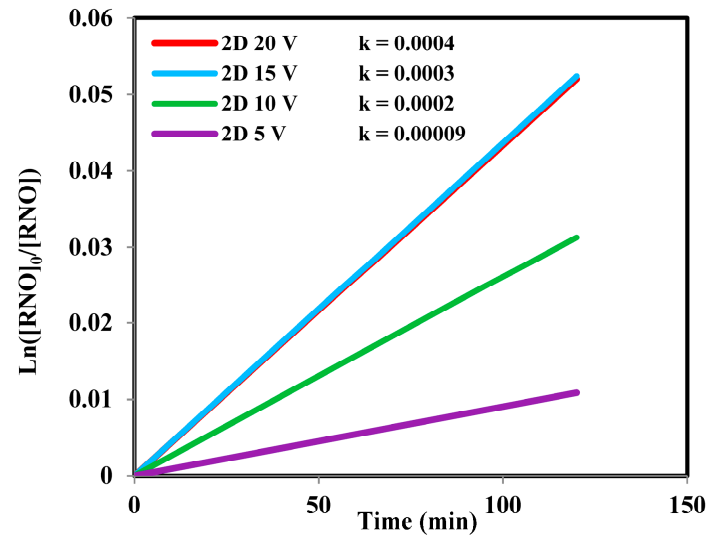

(b)

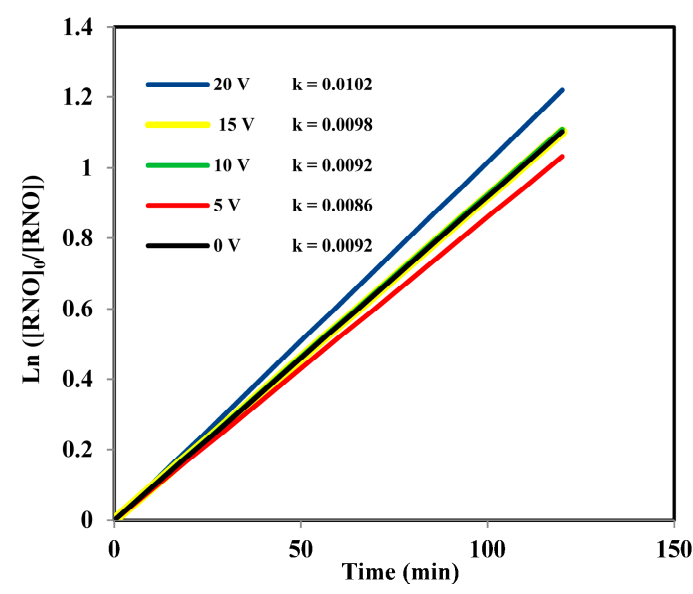

(d)

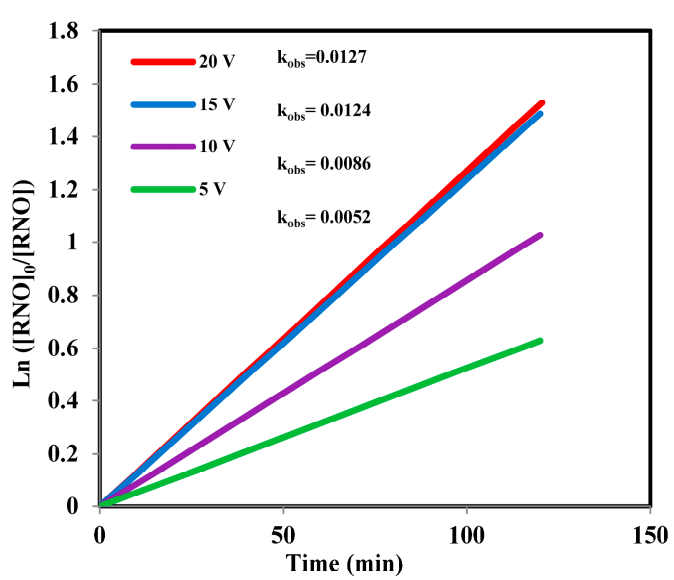

(f)

Figure 4. RNO degradation $(\mathbf{a}, \mathbf{b})$ in a 2D system with corresponding kinetic rate curves, $(\mathbf{c}, \mathbf{d})$ a $3 \mathrm{D}$ system using GAC as particle electrodes with corresponding kinetic rate curves, and (e,f) a 3D system using NCPEs as particle electrodes with corresponding kinetic rate curves. 


\subsection{Synergy Evaluation for GAC and NCPEs Versus Applied Cell Voltage}

Having the kinetic rate constants obtained for single adsorption, two-dimensional and three-dimensional processes from Figure 4, the synergy parameter for each setting was calculated, and the results are compared in Figure 5. In our previous work, $15 \mathrm{~V}$ was found to be the optimum voltage for RNO removal in a 3D system using NCPEs as particle electrodes [19].

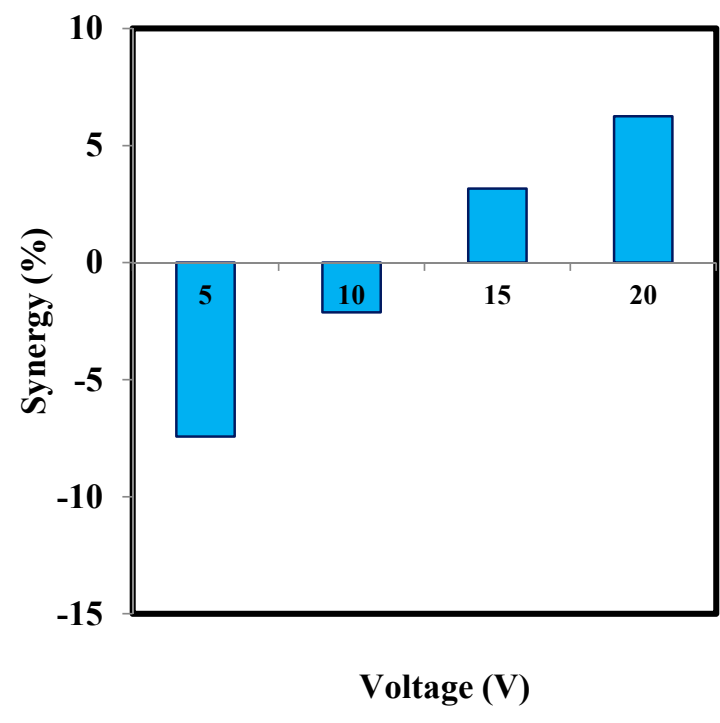

(a)

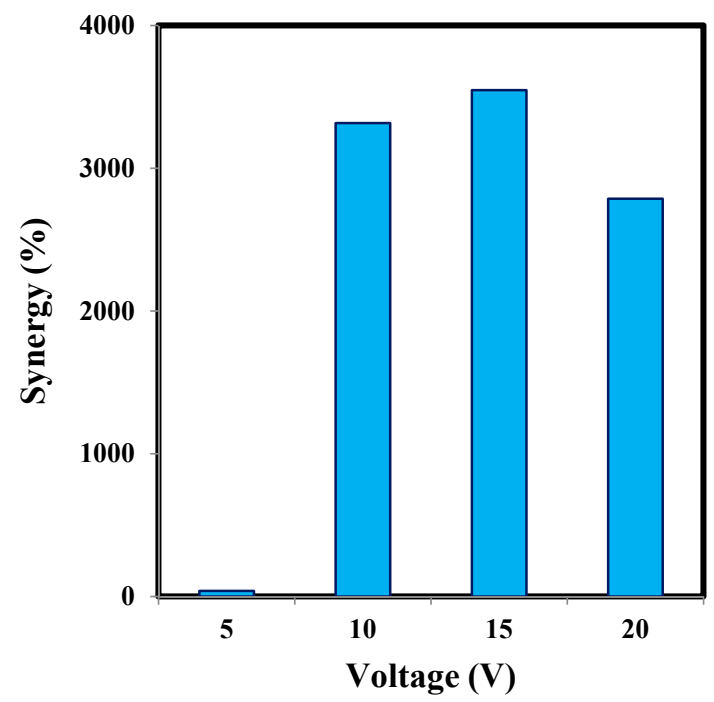

(b)

Figure 5. Comparative study of synergy parameter for RNO decolorization (a) in 3D systems using GACs as particle electrodes and (b) in a 3D system using NCPEs as particle electrodes.

Here, it was attempted to achieve an optimum synergy point ascertaining optimal operating costs with respect to the electric energy consumption of the electrochemical water treatment process.

Making an overall comparison of the values obtained for the synergy parameter of synthesized NCPEs and GACs, the performance superiority of NCPEs to GACs was clear. As shown in Figure 5, the synergy parameter for the activated carbon catalyst was negative below $15 \mathrm{~V}$. However, the synthesized catalyst exhibited the highest synergy parameter value at 5 volts. Moreover, although the synergy parameter in activated carbon increases with increasing voltage, such a trend was not observed for the synthesized catalyst. In other words, the synergy parameter value of the synthesized catalyst declined from 5 to $10 \mathrm{~V}$ and again slightly increased at $15 \mathrm{~V}$ and reached the minimal synergy value at $20 \mathrm{~V}$, which is an opposite trend compared to the activated carbon with the highest synergy value attained at $20 \mathrm{~V}$. By achieving the maximum synergistic effect at $5 \mathrm{~V}$ for the synthesized catalyst, one can discern that by improving the performance of the particle electrodes in the 3D system and by improving its electrochemical properties, it can further decrease electrical energy consumption.

This improvement in the performance of the synthesized catalyst can be attributed to the high ability of NCPEs in hydroxyl radical production. Nitrogen-doped graphene and iron species in synthesized NCPEs create an electronic structure and increase electrical conductivity in particle electrodes, making them quickly polarized in the electric fields, even at low voltages of 5 volts. Then, hydrogen peroxide is produced at nitrogen-doped graphene sites by an oxygen reduction reaction, which instantly converts to hydroxyl radicals on iron sites of NCPEs by an electro-Fenton reaction. Thereafter, these produced hydroxyl radicals can degrade RNO molecules, which is not the case for activated carbon except at very high voltages, and that is why the synergy parameter for activated carbon is only positive at 15 and 20 volts. In the next section, we evaluate the removal of pesticide at the optimum synergy voltage obtained for synthesized NCPEs in a 3D system. 


\subsection{Pesticides Removal at Maximum Synergy}

The removal of pesticides was completed in a three-dimensional electrochemical water treatment process in a solution containing three pesticide compounds, MCPP, MCPA, and BAM at the cell potential of 5 volts corresponding to the optimum synergy point. Pesticide removal at this voltage for MCPA, MCPP, and BAM reached 32\%, 33\%, and 27\%, respectively, within the treatment time of $8 \mathrm{~h}$ (Figure 6).

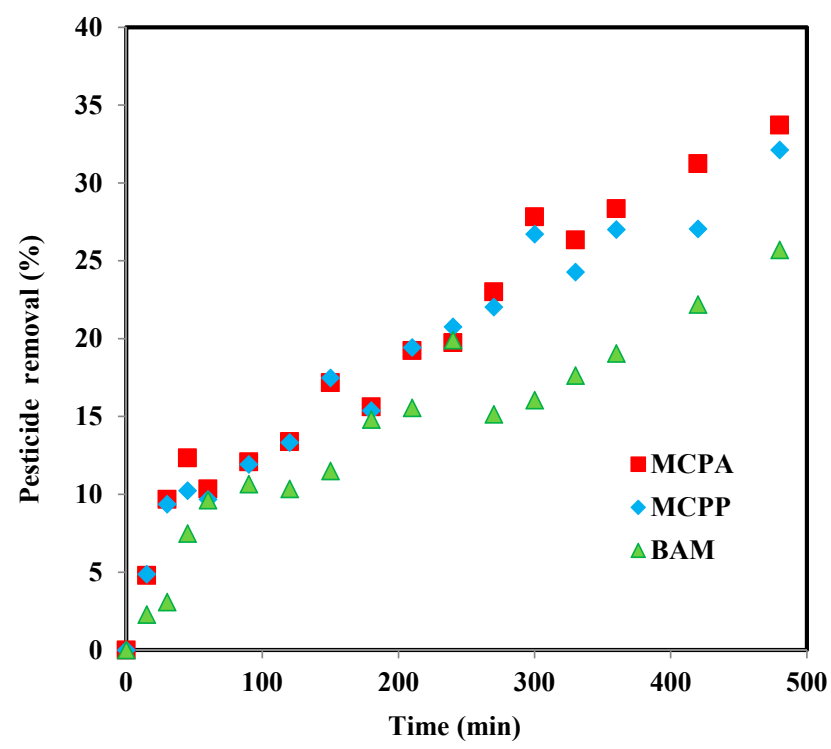

Figure 6. Pesticides removal utilizing a 3D-NCPEs system at maximum synergy voltage (5 V).

The electrochemical degradation pathway of BAM has previously been proposed by Madsen [49], and it can be combined with the interpretation of the data in an illustration of the reaction mechanisms of the 3D process (Figure 7). Once the electric field is applied across the particle electrode bed, oxygen reduction reactions take place on nitrogen-doped graphene sites. The produced hydrogen peroxides in the next step are catalyzed to the highly oxidizing agents hydroxyl radicals by an electro-Fenton reaction on iron sites of the particle electrodes [19] and attack the pesticides to degrade them to organic acids and similar oxidation products.

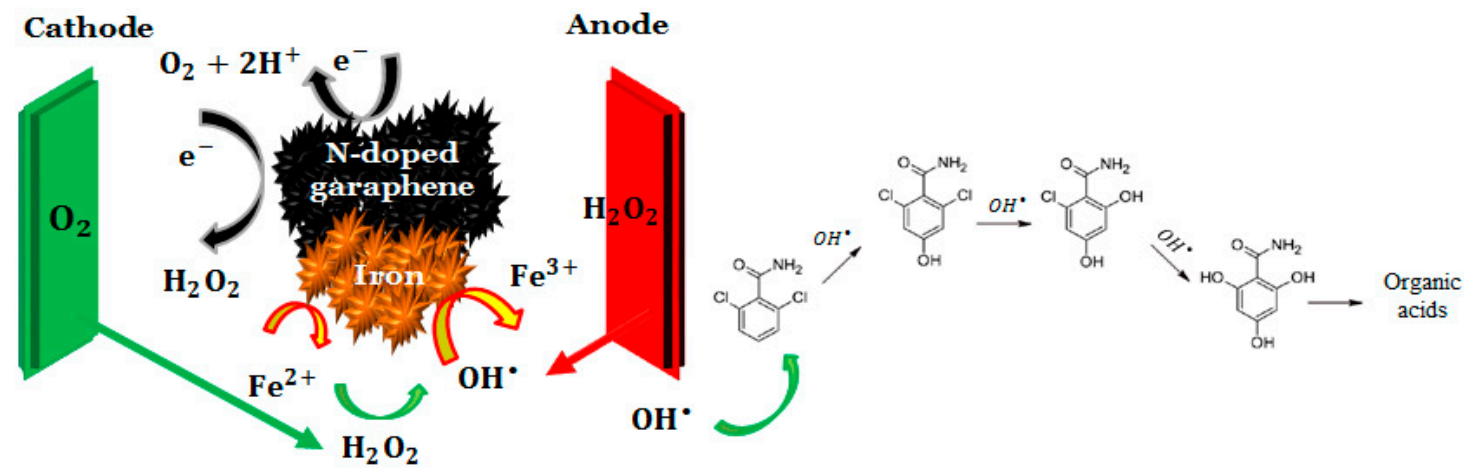

Figure 7. Proposed degradation pathway of model pollutant on synthesized particle electrodes along with the electro-oxidation process of 2,6 dichlorobenzamide (BAM) with permission from [49].

By increasing voltage up to 5 volts, the oxygen reduction reaction on the nitrogen-doped graphene in the NCPEs structure increases the number of produced $\mathrm{H}_{2} \mathrm{O}_{2}$, and these species further convert to hydroxyl radicals with oxidation reactions (including electro-Fenton) on iron sites of the NCPEs; therefore, the produced hydroxyl radicals could degrade the pesticides from water, even at low voltages 
of 5 volts. However, activated carbon can only improve the oxygen reduction reaction in case of higher voltages. This is why the removal of MCPP and MCPA pesticides from water by the 3D-NCPEs process at 5 volts was not significantly different (only 15\%) from that of the 3D-GACs process at 15 volts that was reported previously [10], and the NCPE's performance was even better for removing BAM at 5 volts compared to that of activated carbon at 15 volts. This improved performance of particle electrodes for pesticide degradation could also be attributed to the presence of graphitic and pyridinic nitrogen species in a synthesized catalyst nanostructure [19]. It was reported that pyridinic nitrogen is responsible for creating defect sites and edge planes on graphene sheets that play an important role in catalyzing ORRs [36,50,51].

\subsection{Effect of Background Electrolyte and Indirect Oxidation}

Due to the focus on the microelectrode performance and synergy parameters in the previous sections, DI water without background electrolytes was used as a solvent to minimize the influence of an indirect oxidation reaction on organic removal and to confine degradation to near or at surface reactions. By using sodium sulfate as the background electrolyte, the ionic and electronic conductivity of solution increased; thus, ohmic resistance decreased. This would cause electrochemical water treatment to proceed rapidly. The use of drinking water as a solvent triggered indirect electrochemical oxidation and reduction reactions (active chlorine formation and bulk oxidation, oxygen reduction and hydrogen peroxide catalysis, persulphate formation, etc.), which may influence removal kinetics and energy requirements. The ionic composition of tab water from Esbjerg, Denmark drinking water is listed in Table 1 [22].

RNO decolorization curves using different solvents i.e., DI water, Esbjerg tap water, and DI water with supporting electrolyte of $0.05 \mathrm{M}$ sodium sulfate, are shown in Figure 8 . The conductivity of the mentioned solutions was as follows: DI water: $\approx 6-7 \mu \mathrm{S} / \mathrm{cm}$, tap water: $409.6 \mu \mathrm{S} / \mathrm{cm}, 0.05 \mathrm{M}$ sodium sulfate in DI water: $8.659 \mathrm{mS} / \mathrm{cm}$.

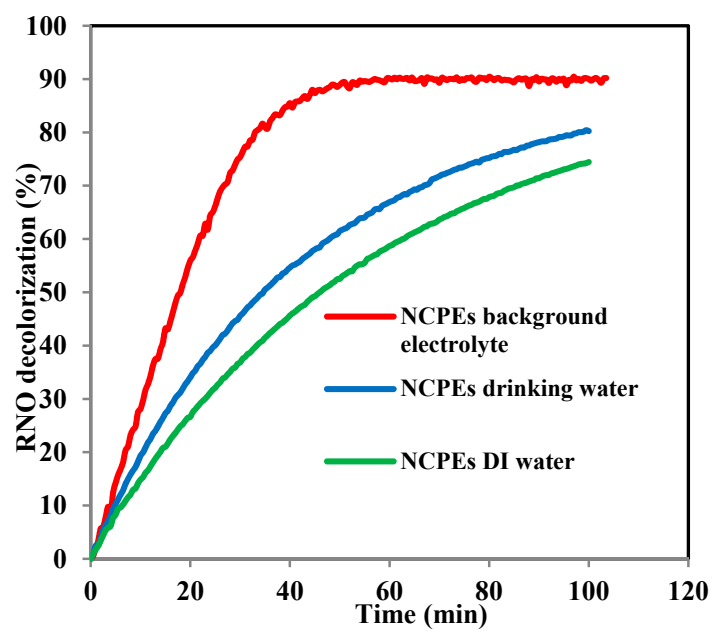

(a)

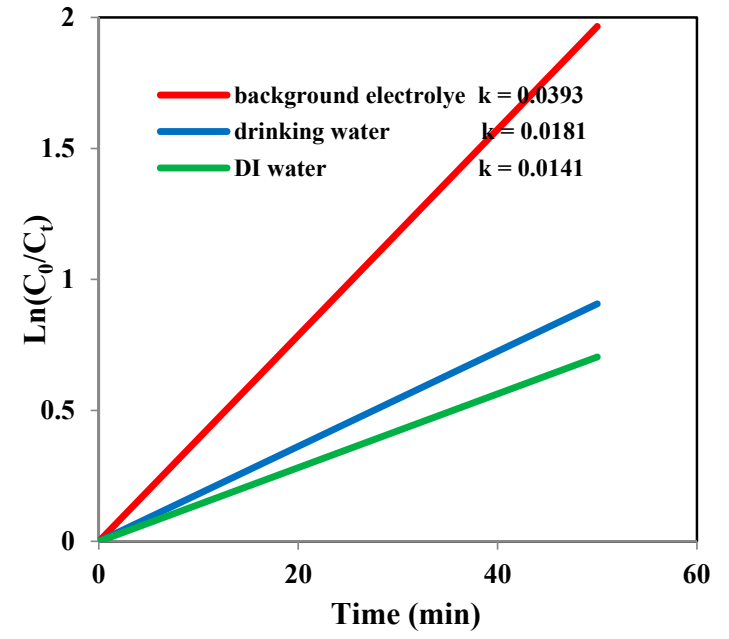

(b)

Figure 8. (a) RNO decolorization in 3D-NCPEs system using different solvents, (b) corresponding kinetic rate curves at $15 \mathrm{~V}$.

As seen in Figure 8, it was clear that the decolorization process occurred much faster in the case of using sodium sulfate as supporting electrolyte, and it reached up to $90 \%$ within only $50 \mathrm{~min}$ of treatment, while the corresponding level in DI water took 5 to $6 \mathrm{~h}$. The rate of RNO decolorization in drinking water was also faster compared to that of DI water, but it was still slower than RNO decolorization with the supporting electrolyte. 


\section{Conclusions}

The synergy parameters in a three-dimensional system were significantly improved by using a newly synthesized particle electrodes compared with activated carbon. The optimum synergy parameter was obtained at $5 \mathrm{~V}$ in 3D-NCPEs system $(\approx 3900 \%)$, whereas in a 3D-GACs system, it was found to be $15 \mathrm{~V}(3 \%)$, showing a high electrochemical activity of synthesized catalyst. Pesticides removal at the optimum synergy voltage was found to be comparable in the case of MCPA and MCPP removal and better in the case of BAM removal compared to that of 3D-GACs at $15 \mathrm{~V}$ determined in previous studies. Investigation of the effect of the supporting electrolyte indicated that adding a background electrolyte increasing the ionic, and the electronic conductivity in the solution significantly accelerates the treatment process. The use of drinking water also increased the indirect electro-oxidation processes and facilitated the RNO decolorization process.

Author Contributions: Conceptualization, H.G., N.L.P., M.E.S., J.M.; methodology, H.G., N.L.P., M.E.S., J.M.; investigation, H.G., N.L.P.; resources, M.E.S., J.M.; writing—original draft preparation, H.G.; writing-review and editing, H.G., M.E.S., J.M.; supervision, M.E.S., J.M.; project administration, J.M. All authors have read and agreed to the published version of the manuscript.

Funding: This research received no external funding.

Acknowledgments: Post doc Mahdi Nikbakht Fini is acknowledged for his support with pesticide analysis.

Conflicts of Interest: The authors declare no conflict of interest.

\section{References}

1. Larsen, T. Source Separation and decentralization for wastewater management. Water Intell. Online $2013,12$. [CrossRef]

2. Zhang, C.; Jiang, Y.; Li, Y.; Hu, Z.; Zhou, L.; Zhou, M. Three-dimensional electrochemical process for wastewater treatment: A general review. Chem. Eng. J. 2013, 228, 455-467. [CrossRef]

3. Hussain, S.N.; de las Heras, N.; Asghar, H.M.A.; Brown, N.W.; Roberts, E.P.L. Disinfection of water by adsorption combined with electrochemical treatment. Water Res. 2014, 54, 170-178. [CrossRef] [PubMed]

4. Garcia, E.A.; Agullo-Barcelo, M.; Bond, P.; Keller, J.; Gernjak, W.; Radjenovic, A. Decentralized grey-water treatment system based on combined adsorption and electrochemical oxidation. In Proceedings of the IWA World Water Congress, Brisbane, Australia, 9-13 October 2016.

5. Li, M.; Zhao, F.; Sillanpää, M.; Meng, Y.; Yin, D. Electrochemical degradation of 2-diethylamino-6-methyl-4hydroxypyrimidine using three-dimensional electrodes reactor with ceramic particle electrodes. Sep. Purif. Technol. 2015, 156, 588-595. [CrossRef]

6. Zhang, L.; Ma, C.; Liu, L.; Pan, J.; Wang, Q. Fabrication of novel particle electrode $\gamma$-Al2O3@ZIF-8 and its application for degradation of Rhodamine B. Water Sci. Technol. 2019, 80, 109-116. [CrossRef] [PubMed]

7. Sun, Y.; Li, P.; Zheng, H.; Zhao, C.; Xiao, X.; Xu, Y.; Sun, W.; Wu, H.; Ren, M. Electrochemical treatment of chloramphenicol using Ti-Sn $/ \gamma$-Al2O3 particle electrodes with a three-dimensional reactor. Chem. Eng. J. 2017, 308, 1233-1242. [CrossRef]

8. Sun, W.; Sun, Y.; Shah, K.J.; Chiang, P.-C.; Zheng, H. Electrocatalytic oxidation of tetracycline by $\mathrm{Bi}-\mathrm{Sn}-\mathrm{Sb} / \gamma$-Al2O3 three-dimensional particle electrode. J. Hazard. Mater. 2019, 370, 24-32. [CrossRef]

9. Zhu, X.; Ni, J.; Xing, X.; Li, H.; Jiang, Y. Synergies between electrochemical oxidation and activated carbon adsorption in three-dimensional boron-doped diamond anode system. Electrochim. Acta 2011, 56, 1270-1274. [CrossRef]

10. Pedersen, N.L.; Fini, M.N.; Molnar, P.K.; Muff, J. Synergy of combined adsorption and electrochemical degradation of aqueous organics by granular activated carbon particulate electrodes. Sep. Purif. Technol. 2019, 208, 51-58. [CrossRef]

11. Zhan, J.; Li, Z.; Yu, G.; Pan, X.; Wang, J.; Zhu, W.; Han, X.; Wang, Y. Enhanced treatment of pharmaceutical wastewater by combining three-dimensional electrochemical process with ozonation to in situ regenerate granular activated carbon particle electrodes. Sep. Purif. Technol. 2019, 208, 12-18. [CrossRef] 
12. Li, X.-Y.; Xu, J.; Cheng, J.-P.; Feng, L.; Shi, Y.-F.; Ji, J. TiO2-SiO2/GAC particles for enhanced electrocatalytic removal of acid orange 7 (AO7) dyeing wastewater in a three-dimensional electrochemical reactor. Sep. Purif. Technol. 2017, 187, 303-310. [CrossRef]

13. Dieckmann, G.R.; Langer, S.H. Selective electrogenerative oxidation of benzyl alcohol with platinum-graphite packed-bed anodes. J. Appl. Electrochem. 1997, 27, 1-8. [CrossRef]

14. Ehdaie, S.; Fleischmann, M.; Jansson, R.E.W. Application of the trickle tower to problems of pollution control. I. The scavenging of metal ions. J. Appl. Electrochem. 1982, 12, 59-67. [CrossRef]

15. El-Ghaoui, E.A.; Jansson, R.E.W.; Moreland, C. Application of the trickle tower to problems of pollution control. II. The direct and indirect oxidation of cyanide. J. Appl. Electrochem. 1982, 12, 69-73. [CrossRef]

16. Xiong, Y.; He, C.; Karlsson, H.T.; Zhu, X. Performance of three-phase three-dimensional electrode reactor for the reduction of COD in simulated wastewater-containing phenol. Chemosphere 2003, 50, 131-136. [CrossRef]

17. Wu, Z.; Cong, Y.; Zhou, M.; Tan, T.-E. p-Nitrophenol abatement by the combination of electrocatalysis and activated carbon. Chem. Eng. J. 2005, 106, 83-90. [CrossRef]

18. Xiong, Y.; Karlsson, H.T. An experimental investigation of chemical oxygen demand removal from the wastewater containing oxalic acid using three-phase three-dimensional electrode reactor. Adv. Environ. Res. 2002, 7, 139-145. [CrossRef]

19. Ghanbarlou, H.; Nasernejad, B.; Fini, M.N.; Simonsen, M.E.; Muff, J. Synthesis of an iron-graphene based particle electrode for pesticide removal in three-dimensional heterogeneous electro-Fenton water treatment system. Chem. Eng. J. 2020, 395, 125025. [CrossRef]

20. Ghanbarlou, H.; Pedersen, N.L.; Fini, M.N.; Muff, J. Synergy optimization for the removal of dye and pesticides from drinking water using granular activated carbon particles in a $3 \mathrm{D}$ electrochemical reactor. Environ. Sci. Pollut. Res. 2020, 27, 22206-22213. [CrossRef]

21. Fini, M.N.; Madsen, H.T.; Muff, J. The effect of water matrix, feed concentration and recovery on the rejection of pesticides using NF/RO membranes in water treatment. Sep. Purif. Technol. 2019, 215, 521-527. [CrossRef]

22. Hylling, O.; Fini, M.N.; Ellegaard-Jensen, L.; Muff, J.; Madsen, H.T.; Aamand, J.; Hansen, L.H. A novel hybrid concept for implementation in drinking water treatment targets micropollutant removal by combining membrane filtration with biodegradation. Sci. Total Environ. 2019, 694, 133710. [CrossRef] [PubMed]

23. Thorling, W.B.L.; Hansen, B.; Larsen, C.L.; Mielby, S.; Troldborg, L.; Sørensen, B.L. Grundvand. Status og udvikling, 1989-2017. 2018. Technical Report, ISBN Online: 978-87-7871-522-7. Available online: www.grundvandsovervaagning.dk (accessed on 7 November 2020).

24. Xue, Y.; Wang, Y.; Pan, Z.; Zhang, C. Metal-organic frameworks derived cobalt encapsulated in porous nitrogen-doped carbon nanostructure towards highly efficient and durable oxygen reduction reaction electrocatalysis. J. Power Sources 2020, 451, 227747. [CrossRef]

25. Xiong, W.; Li, H.; Cao, R. Nitrogen and sulfur dual-doped hollow mesoporous carbon spheres as efficient metal-free catalyst for oxygen reduction reaction. Inorg. Chem. Commun. 2020, 114, 107848. [CrossRef]

26. Kumaresan, T.K.; Gunasekaran, S.S.; Elumalai, S.K.; Masilamani, S.A.; Raman, K.; Rengarajan, B.; Subashchandrabose, R. Promising nature-based nitrogen-doped porous carbon nanomaterial derived from borassus flabellifer male inflorescence as superior metal-free electrocatalyst for oxygen reduction reaction. Int. J. Hydrog. Energy 2019, 44, 25918-25929. [CrossRef]

27. Ghanbarlou, H.; Rowshanzamir, S.; Parnian, M.J.; Mehri, F. Comparison of nitrogen-doped graphene and carbon nanotubes as supporting material for iron and cobalt nanoparticle electrocatalysts toward oxygen reduction reaction in alkaline media for fuel cell applications. Int. J. Hydrog. Energy 2016, 41, 14665-14675. [CrossRef]

28. Ghanbarlou, H.; Rowshanzamir, S.; Kazeminasab, B.; Parnian, M.J. Non-precious metal nanoparticles supported on nitrogen-doped graphene as a promising catalyst for oxygen reduction reaction: Synthesis, characterization and electrocatalytic performance. J. Power Sources 2015, 273, 981-989. [CrossRef]

29. Wu, X.; Chen, K.; Lin, Z.; Zhang, Y.; Meng, H. Nitrogen doped graphitic carbon from biomass as non noble metal catalyst for oxygen reduction reaction. Mater. Today Energy 2019, 13, 100-108. [CrossRef]

30. Wang, X.; Yuan, C.; Shao, C.; Zhuang, S.; Ye, J.; Li, B. Enhancing oxygen reduction reaction by using metal-free nitrogen-doped carbon black as cathode catalysts in microbial fuel cells treating wastewater. Environ. Res. 2020, 182, 109011. [CrossRef] 
31. Niu, W.-J.; Wang, Y.-P.; He, J.-Z.; Liu, W.-W.; Liu, M.-C.; Shan, D.; Lee, L.; Chueh, Y.-L. Highly stable nitrogen-doped carbon nanotubes derived from carbon dots and metal-organic frameworks toward excellent efficient electrocatalyst for oxygen reduction reaction. Nano Energy 2019, 63, 103788. [CrossRef]

32. Xu, J.; Shi, L.; Wang, J.; Lu, S.; Wang, Y.; Gao, G.; Ding, S. Hierarchical micro/mesoporous nitrogen-doped carbons derived from hypercrosslinked polymers for highly efficient oxygen reduction reaction. Carbon 2018, 138, 348-356. [CrossRef]

33. Fu, X.; Liu, Y.; Cao, X.; Jin, J.; Liu, Q.; Zhang, J. FeCo-Nx embedded graphene as high performance catalysts for oxygen reduction reaction. Appl. Catal. B Environ. 2013, 130-131, 143-151. [CrossRef]

34. Lim, S.H.; Li, Z.; Poh, C.K.; Lai, L.; Lin, J. Highly active non-precious metal catalyst based on poly(vinylpyrrolidone)-wrapped carbon nanotubes complexed with iron-cobalt metal ions for oxygen reduction reaction. J. Power Sources 2012, 214, 15-20. [CrossRef]

35. Lin, Z.; Waller, G.H.; Liu, Y.; Liu, M.; Wong, C.-P. Simple preparation of nanoporous few-layer nitrogen-doped graphene for use as an efficient electrocatalyst for oxygen reduction and oxygen evolution reactions. Carbon 2013, 53, 130-136. [CrossRef]

36. Subramanian, N.P.; Li, X.; Nallathambi, V.; Kumaraguru, S.P.; Colon-Mercado, H.; Wu, G.; Lee, J.-W.; Popov, B.N. Nitrogen-modified carbon-based catalysts for oxygen reduction reaction in polymer electrolyte membrane fuel cells. J. Power Sources 2009, 188, 38-44. [CrossRef]

37. Zheng, B.; Wang, J.; Wang, F.-B.; Xia, X.-H. Synthesis of nitrogen doped graphene with high electrocatalytic activity toward oxygen reduction reaction. Electrochem. Commun. 2013, 28, 24-26. [CrossRef]

38. Zhang, Y.; Fugane, K.; Mori, T.; Niu, L.; Ye, J. Wet chemical synthesis of nitrogen-doped graphene towards oxygen reduction electrocatalysts without high-temperature pyrolysis. J. Mater. Chem. 2012, 22, 6575-6580. [CrossRef]

39. Mo, Z.; Liao, S.; Zheng, Y.; Fu, Z. Preparation of nitrogen-doped carbon nanotube arrays and their catalysis towards cathodic oxygen reduction in acidic and alkaline media. Carbon 2012, 50, 2620-2627. [CrossRef]

40. Bai, J.; Zhu, Q.; Lv, Z.; Dong, H.; Yu, J.; Dong, L. Nitrogen-doped graphene as catalysts and catalyst supports for oxygen reduction in both acidic and alkaline solutions. Int. J. Hydrog. Energy 2013, 38, 1413-1418. [CrossRef]

41. Luo, Z.; Lim, S.; Tian, Z.; Shang, J.; Lai, L.; MacDonald, B.; Fu, C.; Shen, Z.; Yu, T.; Lin, J. Pyridinic N doped graphene: Synthesis, electronic structure, and electrocatalytic property. J. Mater. Chem. 2011, 21, 8038-8044. [CrossRef]

42. Lin, Z.; Waller, G.; Liu, Y.; Liu, M.; Wong, C.-P. Facile synthesis of nitrogen-doped graphene via pyrolysis of graphene oxide and urea, and its electrocatalytic activity toward the oxygen-reduction reaction. Adv. Energy Mater. 2012, 2, 884-888. [CrossRef]

43. Yu, F.; Zhou, M.; Yu, X. Cost-effective electro-Fenton using modified graphite felt that dramatically enhanced on $\mathrm{H} 2 \mathrm{O} 2$ electro-generation without external aeration. Electrochim. Acta 2015, 163, 182-189. [CrossRef]

44. Hou, B.; Ren, B.; Deng, R.; Zhu, G.; Wang, Z.; Li, Z. Three-dimensional electro-Fenton oxidation of $\mathrm{N}$-heterocyclic compounds with a novel catalytic particle electrode: High activity, wide $\mathrm{pH}$ range and catalytic mechanism. RSC Adv. 2017, 7, 15455-15462. [CrossRef]

45. Görmez, F.; Görmez, Ö.; Gözmen, B.; Kalderis, D. Degradation of chloramphenicol and metronidazole by electro-Fenton process using graphene oxide-Fe3O4 as heterogeneous catalyst. J. Environ. Chem. Eng. 2019, 7, 102990. [CrossRef]

46. Zhang, Y.; Chen, Z.; Wu, P.; Duan, Y.; Zhou, L.; Lai, Y.; Wang, F.; Li, S. Three-dimensional heterogeneous Electro-Fenton system with a novel catalytic particle electrode for Bisphenol A removal. J. Hazard. Mater. 2019, 393, 120448. [CrossRef] [PubMed]

47. Zhang, C.; Zhou, M.; Ren, G.; Yu, X.; Ma, L.; Yang, J.; Yu, F. Heterogeneous electro-Fenton using modified iron-carbon as catalyst for 2,4-dichlorophenol degradation: Influence factors, mechanism and degradation pathway. Water Res. 2015, 70, 414-424. [CrossRef] [PubMed]

48. Muff, J.; Bennedsen, L.R.; Sogaard, E. Study of electrochemical bleaching of p-nitrosodimethylaniline and its role as hydroxyl radical probe compound. J. Appl. Electrochem. 2011, 41, 599-607. [CrossRef]

49. Madsen, H.T.; Søgaard, E.G.; Muff, J. Study of degradation intermediates formed during electrochemical oxidation of pesticide residue 2,6-dichlorobenzamide (BAM) at boron doped diamond (BDD) and platinum-iridium anodes. Chemosphere 2014, 109, 84-91. [CrossRef] 
50. Matter, P.H.; Zhang, L.; Ozkan, U.S. The role of nanostructure in nitrogen-containing carbon catalysts for the oxygen reduction reaction. J. Catal. 2006, 239, 83-96. [CrossRef]

51. Montoya, A.; Mondragón, F.; Truong, T.N. Kinetics of nitric oxide desorption from carbonaceous surfaces. Fuel Process. Technol. 2002, 77-78, 453-458. [CrossRef]

Publisher's Note: MDPI stays neutral with regard to jurisdictional claims in published maps and institutional affiliations.

(C) 2020 by the authors. Licensee MDPI, Basel, Switzerland. This article is an open access article distributed under the terms and conditions of the Creative Commons Attribution (CC BY) license (http://creativecommons.org/licenses/by/4.0/). 